\title{
Cardiovascular side effects of inhaled salbutamol in hypoxic asthmatic patients
}

\author{
J Burggraaf, R G J Westendorp, J C C M in't Veen, R C Schoemaker, P J Sterk, \\ A F Cohen, G J Blauw
}

\begin{abstract}
Background-Beta-2 adrenoceptor agonists have been associated with sudden death in asthma patients but the cause and underlying mechanism are unclear. Animal experiments indicate that the combination of hypoxia and $\beta_{2}$ agonists may result in detrimental cardiovascular effects. A study was undertaken to investigate the effect of hypoxia on the systemic vascular effects of salbutamol in patients with asthma who are hypoxic by assessing forearm blood flow (FBF) as a measure of peripheral vasodilatation.
\end{abstract}

Methods-Eight men with mild asthma underwent the followingtreatments:normoxia + placebo (NP), normoxia + salbutamol (NS), hypoxia + placebo (HP), and hypoxia + salbutamol (HS). The period of mask breathing started at $t=0$ minutes, lasted for $\mathbf{6 0}$ minutes, and at $\mathbf{3 0}$ minutes $800 \mu \mathrm{g}$ salbutamol was inhaled. The experiment was completed $30 \mathrm{~min}$ utes after the inhalation ( $t=60$ minutes). For the hypoxia treatment the $\mathrm{Spo}_{2}$ level was $82 \%$. Differences between treatments were sought using factorial ANOVA on percentage change from the pretreatment value.

Results-There were no significant differences in blood pressure and potassium levels between the treatments. After 60 minutes the increase in FBF was $13 \%$ (95\% CI -12 to 39) more for HP treatment than for NP, $21 \%(95 \%$ CI -5 to 46$)$ more for NS than for NP, and $32 \%(95 \%$ CI 7 to 58) more for HS than for HP $(p=0.016)$. The inhalation of salbutamol during hypoxia resulted in a significant increase in FBF of $45 \%$ (95\% CI 20 to 71$)$ compared with NP $(p=0.001)$.

Conclusion-Patients with asthma who are hypoxic and inhale $\beta_{2}$ agonists have serious systemic vascular side effects which may be an additional explanation for the association between asthma treatment and sudden death.

(Thorax 2001;56:567-569)

Keywords: asthma; hypoxia; $\beta_{2}$ agonists
Beta- 2 adrenoceptor agonists ( $\beta_{2}$ agonists) are the most effective and widely used bronchodilator drugs for treatment of acute exacerbations of asthma. However, ever since their introduction, $\beta$ agonists have been associated with sudden death in asthma. ${ }^{1}$ Many explanations for the association of sudden death and asthma treatment have been proposed and refuted..$^{2-7}$ Among the factors that may play an important role are the severity of asthma, ${ }^{8}$ treatment intensity, ${ }^{9}$ socioeconomic factors, ${ }^{10}$ cardiac arrhythmias (due to QT prolongation and/or changes in potassium levels), and the use of $\beta$ agonists. ${ }^{511}$ It appears that most of the sudden deaths occur outside hospital. ${ }^{12}$ In contrast with the situation outside hospital, clinical treatment of exacerbations of asthma in hospital involves the concomitant administration of $\beta$ agonists and oxygen. It can be hypothesised that administration of $\beta$ agonists during hypoxia is potentially detrimental and provides an alternative explanation for the association with sudden death. ${ }^{13}$ Experimental studies have shown that $\beta$ agonists are lethal in dogs when the animals are hypoxic. ${ }^{14}$ We have recently shown in volunteers exposed to hypoxia that a similar mechanism may also apply to humans. ${ }^{15}$ Furthermore, it has been shown that inhalation of $\beta$ agonists can worsen hypoxia. ${ }^{16}$ The present study was designed to investigate the effect of hypoxia on the systemic vascular effects of salbutamol in patients with asthma who are hypoxic.

\section{Methods}

The study protocol was approved by the medical ethics committee of Leiden University Medical Center. After obtaining informed consent, eight men with mild asthma (aged $21-26$ years, using $\beta$ agonists on demand only) who complied with the international classification of intermittent mild asthma (NNHLBI/ WHO Workshop 1995) participated in a double blind, placebo controlled, four way, crossover study. The following interventions were investigated: normoxia and placebo, normoxia and inhaled salbutamol, hypoxia and placebo, and hypoxia with salbutamol inhalation. Each intervention was separated by a one week washout period. During the experiments the subjects breathed ambient air or a variable $\mathrm{N}_{2} / \mathrm{O}_{2}$ mixture through a well fitting face mask. The $\mathrm{N}_{2} / \mathrm{O}_{2}$ mixture was continuously adjusted 
Table 1 Mean (SD) values $(n=8)$ for mean arterial pressure $(M A P)$, heart rate (HR), QTc interval, forearm vascular resistance (FVR), and serum potassium levels $\left(\mathrm{K}^{+}\right)$at baseline $(t=0)$ and at the end of the experiment $(t=60)$

\begin{tabular}{|c|c|c|c|c|c|c|c|c|c|c|}
\hline & \multicolumn{2}{|c|}{$M A P(m m H g)$} & \multicolumn{2}{|l|}{$H R(b p m)$} & \multicolumn{2}{|l|}{$Q T c(m s)$} & \multicolumn{2}{|c|}{$F V R(m m H g / \% F B F)$} & \multicolumn{2}{|l|}{$K^{+}(m m o l / l)$} \\
\hline & $t=0$ & $t=60$ & $t=0$ & $t=60$ & $t=0$ & $t=60$ & $t=0$ & $t=60$ & $t=0$ & $t=60$ \\
\hline NP & $81.7(6.9)$ & $82.4(9.3)$ & $69.0(8.1)$ & $64.8(11.5)$ & $390(20)$ & $395(12)$ & $29.3(14.2)$ & $28.3(13.6)$ & $4.22(0.14)$ & $4.10(0.37)$ \\
\hline $\mathrm{HP}$ & $82.5(7.2)$ & $82.5(7.8)$ & $65.0(9.4)$ & $70.9(10.9)^{\star \star}$ & $389(15)$ & $397(16)$ & $26.2(11.4)$ & $23.9(13.6)$ & $3.99(0.21)$ & $4.01(0.15)$ \\
\hline NS & $81.6(8.1)$ & $83.5(7.9)$ & $65.1(8.4)$ & $66.8(13.3)$ & $393(14)$ & $398(12)$ & $25.0(7.4)$ & $21.1(8.3)$ & $4.06(0.28)$ & $4.02(0.35)$ \\
\hline & $81.8(3.9)$ & $82.9(8.6)$ & $62.4(8.7)$ & $76.3(9.2)^{\star \star \star}$ & $384(18)$ & $409(23)^{\star}$ & $30.9(9.5)$ & $21.9(8.9)^{\star \star}$ & $4.08(0.26)$ & $3.89(0.17)$ \\
\hline$p$ value & 0.857 & & $<0.001$ & & 0.037 & & 0.034 & & 0.495 & \\
\hline
\end{tabular}

$\mathrm{NP}=$ normoxia + placebo $\mathrm{HP}=$ hypoxia + placebo NS $=$ normoxia + salbutamol $; \mathrm{HS}=$ hypoxia + salbutamol

Significant differences from NP as percentage change from $t=0$ value: ${ }^{\star} \mathrm{p}<0.05 ;{ }^{\star \star} \mathrm{p}<0.01 ; ;^{\star \star \star} \mathrm{p}<0.001$.

to obtain a peripheral oxygen saturation $\left(\mathrm{SpO}_{2}\right)$ of $80 \%$. Salbutamol $800 \mu \mathrm{g}$ and placebo were administered double blind as metered dose aerosols via a spacer device (Volumatic). After obtaining stable baseline haemodynamic values (forearm blood flow (FBF), mean arterial pressure (MAP), and heart rate) the subjects breathed either ambient air (normoxia) or an $\mathrm{N}_{2} / \mathrm{O}_{2}$ mixture (hypoxia) for 60 minutes. Salbutamol or placebo were administered after 30 minutes mask breathing. FBF was measured 30 and 60 minutes after baseline using computerised venous occlusion plethysmography. ${ }^{15}$ Monitoring of one lead ECG and $\mathrm{SpO}_{2}$ was done continuously. At regular time intervals blood pressure (oscillometric) was measured and 12-lead ECGs were recorded. Forearm vascular resistance (FVR) was calculated as MAP divided by $\mathrm{FBF}$ (in $\mathrm{mmHg} / \% \mathrm{FBF}$ ). The interventions were compared using factorial ANOVA (factors subject and treatment) on the percentage change after 60 minutes relative to the baseline value. Contrasts between treatments within the ANOVA model are presented with $95 \%$ confidence intervals or by reporting significant contrasts.

\section{Results}

All subjects completed the study without clinically significant adverse events. Subjects could not distinguish whether they had been exposed to hypoxia or normoxia. Hypoxia was easily achieved and maintained at an $\mathrm{SpO}_{2}$ level of 82 (3) $\%$. In three subjects who were administered salbutamol during hypoxia $\mathrm{Spo}_{2}$ levels rapidly decreased below $80 \%$ (to $60-70 \%$ ), requiring

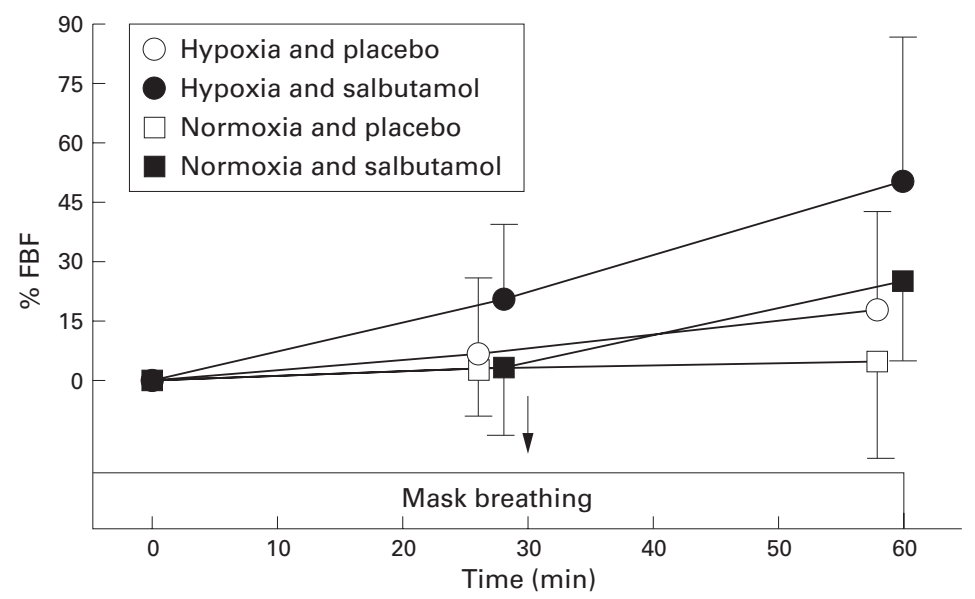

Figure 1 Mean (SD) percentage change in forearm blood flow (FBF) induced by placebo (normoxia + placebo), hypoxia (hypoxia + placebo), salbutamol alone (normoxia + salbutamol), and hypoxia with salbutamol (hypoxia + salbutamol). The arrow indicates inhalation of placebo/salbutamol. cessation of $\mathrm{N}_{2}$ for several minutes. Salbutamol during normoxia did not influence $\mathrm{SpO}_{2}$. Hypoxia did not greatly influence MAP, QTc interval, or potassium levels compared with normoxia (table 1). Salbutamol had no effect on MAP and only a minor effect on QTc $(<7 \%$ prolongation) and potassium levels $(<5 \%$ decrease) during both hypoxia and normoxia. After 60 minutes the increase in heart rate was $16 \%$ (95\% CI 6 to 26) more for hypoxia/ placebo than for normoxia/placebo. The increase in heart rate was $9 \%(95 \% \mathrm{CI}-2$ to 19$)$ more for normoxia/salbutamol than for normoxia/placebo, and $13 \%$ (95\% CI 3 to 24 ) more for hypoxia/salbutamol than for hypoxia/ placebo. After 60 minutes the increase in FBF was $13 \%$ (95\% CI -12 to 39$)$ more for hypoxia/placebo than for normoxia/placebo (fig 1). The increase in $\mathrm{FBF}$ was $21 \%$ (95\% CI -5 to 46 ) more for normoxia/salbutamol than for normoxia/placebo, and 32\% (95\% CI 7 to 58) more for hypoxia/salbutamol than for hypoxia/placebo $(p=0.016)$. Inhalation of salbutamol during hypoxia resulted in a significant increase in $\mathrm{FBF}$ of $45 \%$ (95\% CI 20 to 71$)$ compared with normoxia/placebo $(\mathrm{p}=0.001)$.

\section{Discussion}

This study has shown that patients with asthma who were hypoxic and inhaled salbutamol at a relatively low dose experienced significant and potentially detrimental cardiovascular effects because of substantial vasodilatation and possibly pulmonary shunting. The $45 \%$ increase in $\mathrm{FBF}$ (or 30\% decrease in FVR) is of the same order of magnitude as that observed after vasodilators such as $0.6-0.9 \mathrm{mg}$ sublingual nitrogylcerin $(35 \% \text { decrease in } \mathrm{FVR})^{17}$ or $10 \mathrm{mg}$ oral felodipine $(30 \%$ increase in $\mathrm{FBF}){ }^{18}$

The conclusion that salbutamol during hypoxia may have caused pulmonary shunting was based upon the observation that, in three of the eight subjects, $\mathrm{SpO}_{2}$ levels declined rapidly after inhalation. Obviously, this prompted immediate cessation of breathing of $\mathrm{N}_{2}$ and made it impossible to test formally whether or not this observation was related by chance to the combination of hypoxia and salbutamol. Nevertheless, the observation seems to confirm previous data showing that $\beta_{2}$ agonists can induce pulmonary shunting. ${ }^{16}$

This study therefore provides an additional explanation for the association between the use of $\beta$ agonists and sudden death in asthma. Salbutamol did not greatly influence the QTC interval or potassium level. This is in agreement with previous studies showing that, with 
the salbutamol dose used in this study, only minor or no changes in these parameters occurred..$^{19}$ It was found that both hypoxia and inhalation of salbutamol induced peripheral vasodilatation, but these effects hardly reached statistical significance. In contrast, the combination of salbutamol and hypoxia resulted in profound cardiovascular effects evidenced by a significant increase in $\mathrm{FBF}$, reflecting a reduction in peripheral vascular resistance. Such a mechanism may result in a diminished venous return, especially when the patient is in the upright position, eliciting the Bezold-Jarisch reflex and subsequent cardiac arrest. ${ }^{20}$

In conclusion, inhaled salbutamol during hypoxia causes significant cardiovascular effects that can be detrimental in compromised patients. Asthmatic patients in respiratory distress should be given $\beta_{2}$ agonists and oxygen concomitantly whenever possible.

1 Suissa S, Ernst P, Boivin J-F, et al. A cohort analysis of excess mortality in asthma and the use of inhaled $\beta$-agonists. Am $\mathcal{F}$ Respir Crit Care Med 1994;149:604-10.

2 Fuller RW. The asthma death problem revisited. Br 7 Clin Pharmacol 1996;42:11-14.

3 Hindi-Alexander MC, Middleton EJ. Asthma deaths: are they preventable? N Engl Reg Allergy Proc 1986;7:462-6.

4 Garrett JE, Lanes SF, Kolbe J, et al. Risk of severe life threatening asthma and beta agonist type: an example of confounding by severity. Thorax 1996;51:1093-9.

5 Beasley R, Burgess C, Pearce N, et al. Confounding by severity does not explain the association between fenoterol and asthma death. Clin Exp Allergy 1994;24:660-8.
$6 \mathrm{McFadden}$ ERI. The beta 2-agonist controversy revisited. Ann Allergy Asthma Immunol 1995;75:173-6.

7 Arrighi HM. US asthma mortality: 1941 to 1989 . Ann Allergy Asthma Immunol 1995;74:321-6.

8 Barriot P, Riou B. Prevention of fatal asthma. Chest 1987;92:460-6.

9 Jalaludin BB, Smith MA, Chey T, et al. Risk factors for asthma deaths: a population-based, case-control study. Aust NZ 7 Public Health 1999;23:595-600.

10 Corn B, Hamrung G, Ellis A, et al. Patterns of asthma death and near-death in an inner city tertiary care teaching hospital. F Asthma 1995;32:405-12.

11 Pearce N, Grainger J, Atkinson M, et al. Case-control study of prescribed fenoterol and death from asthma in New Zealand, 1977-81. Thorax 1990;45:170-5.

12 Somerville M, Williams EM, Pearson MG. Asthma deaths in Mersey region 1989-1990. F Public Health Med 1995;17: 397-403.

13 Blauw GJ, Westendorp RGJ. Asthma deaths in New Zealand: whodunnit? Lancet 1995;345:2-3.

14 Collins IWE, McDevitt DG, Shanks RG, et al. The cardiotoxicity of isoprenaline during hypoxia. $\mathrm{Br} f$ Pharmacol 1969;36:35-45.

15 Blauw GJ, Westendorp RGJ, Simons $M$, et al. $\beta$-Adrenergic receptors contribute to hypoxaemia induced vasodilatation in man. Br f Clin Pharmacol 1995;40:453-8.

16 Gross NJ, Bankwala Z. Effects of an anticholinergic bronchodilator on arterial blood gases of hypoxic patients with chronic obstructive pulmonary disease. Comparison with a beta-adrenergic agent. Am f Respir Dis 1987;136: 1091-4.

17 Mason DT, Braunwald E. The effects of nitroglycerin and amyl nitrite on arteriolar and venous tone in the human forearm. Circulation 1965;32:755-66.

18 Bengtsson-Hasselgren B, Ronn O, Blychert LO, et al. Acute effects of felodipine and nifedipine on hepatic and forearm blood flow in healthy men. Eur $\mathcal{f}$ Clin Pharmacol 1990;38:529-33.

19 Crane J, Burgess C, Beasley R. Cardiovascular and hypokalaemic effects of inhaled salbuatomol, fenoterol, and isoprenaline. Thorax 1989;44:136-40.

20 Westendorp RGJ, Blauw GJ, Frölich M, et al. Hypoxic syncope. Aviat Space Environ Med 1997;68:410-14.

\title{
Prevalence of asthma among schoolchildren in Patras, Greece: three surveys over 20 years
}

\author{
M Anthracopoulos, A Karatza, E Liolios, M Triga, K Triantou, K Priftis
}

Department of

Paediatrics,

Respiratory Unit,

University of Patras,

Greece

M Anthracopoulos

A Karatza

E Liolios

M Triga

K Triantou

Department of Allergy,

Penteli Children's

Hospital, Athens,

Greece

K Priftis

Correspondence to:

Dr M Anthracopoulos,

7 Miaoulis Street,

Agios Vassilios, Patras

26500 Greece

manthra@otenet.gr

Received 11 August 2000

Returned to authors

21 October 2000

Revised version received

15 January 2001

Accepted for publication

26 February 2001

\begin{abstract}
Background-The aim of the present study was to compare the prevalence of asthma among schoolchildren in 1978, 1991, and 1998 in Patras, Greece.

Methods-The study populations of the three comparable cross sectional surveys comprised third and fourth grade public school children in Patras, Greece. Sample sizes in 1978, 1991, and 1998 were 3735, 2952 and 3397 children and response rates were $80.4 \%, 81.9 \%$, and $90.6 \%$, respectively. Prevalence of current, non-current, and lifetime asthma or recurrent wheezing was determined by parental questionnaire. Personal communication with the parents of asthmatic children in 1991 and 1998 provided data on lost schooldays.

Results-Prevalence rates of current asthma or wheezing in 1978, 1991, and 1998 were $1.5 \%, 4.6 \%$, and $6.0 \%$, respectively (1978-91: $\mathrm{p}=0.01,1991-98: \mathrm{p}=0.02,1978-98$ : $p=0.03$ ). Lifetime prevalences of asthma or wheezing in 1991 and 1998 were $8.0 \%$
\end{abstract}

and $9.6 \%$, respectively $(p=0.03)$. Current diagnosed asthma increased proportionally to diagnosed wheezing during 199198. The number of schooldays lost in the previous 2 years because of asthma did not change $(p>0.1)$ between 1991 (0.31 per child) and 1998 (0.34 per child).

Conclusions-Our results support a true increase in the prevalence of current and lifetime asthma in the last 20 years among pre-adolescent children in Patras, Greece. Thorax 2001;56:569-571

Keywords: asthma prevalence; wheezing; childhood

Although unequivocal evidence is lacking, ${ }^{1}$ a large body of data supports the impression that the prevalence of asthma has increased in the last decades. ${ }^{2-4}$ Data from Greece on the prevalence of asthma are scarce ${ }^{5}$ and there are no longitudinal data published to date. In 1978 a cross sectional survey estimated the prevalence of asthma among schoolchildren in the city of 
Table 1 Total number and prevalence (\%) of current, non-current and lifetime asthma, hospital admissions, and lost schooldays due to asthma or wheezing in 1978, 1991, and 1998 surveys

\begin{tabular}{llrr}
\hline & $1978(n=3003)$ & $1991(n=2417)$ & $1998(n=3076)$ \\
\hline Current asthma or wheezing & $45(1.5 \%)$ & $112(4.6 \%)$ & $184(6.0 \%)$ \\
Non-current asthma or wheezing & - & $82(3.4 \%)$ & $112(3.6 \%)$ \\
Lifetime asthma or wheezing & - & $194(8.0 \%)$ & $296(9.6 \%)$ \\
Ever hospitalised for asthma or wheezing & - & $57(2.4 \%)$ & $91(3.0 \%)$ \\
$\begin{array}{l}\text { Mean number of lost schooldays due to } \\
\text { asthma or wheezing in the last 2 years: }\end{array}$ & - & & \\
$\quad$ Total sample & - & 0.31 & 0.34 \\
$\quad$ Current asthmatics & & 6.75 & 5.70 \\
\hline
\end{tabular}

Patras. ${ }^{6}$ In the present study, using identical methodology, we have compared the data of that survey with that of two surveys conducted in 1991 and 1998 in order to determine possible changes in the prevalence of asthma over the last 20 years.

\section{Methods}

The target populations of all three surveys were schoolchildren in the third and fourth grade of primary public schools - that is, children aged 8-10 years - in the city of Patras, Greece. In the 1978 survey there were 3735 children from 43 schools, ${ }^{7}$ in the 1991 survey there were 2952 children from 42 schools, and in the 1998 survey there were 3397 children from 44 schools. Forty schools were common in all three surveys and the rest were situated in neighbouring areas. Study populations included over $80 \%$ of the target populations. No school sample consisted of more than $10 \%$ from non-Greek ethnic origin groups.

The following standard parental questionnaire was distributed in all three surveys: (1) Has a physician stated that your child had asthma in the last 2 years? (2) Has a physician stated on two or more separate occasions that your child had wheezing in the last 2 years? (3) Has a physician stated that your child had asthma prior to 2 years ago? (4) Has a physician stated on two or more separate occasions that your child had wheezing prior to 2 years ago? Note: If in doubt about your answer, please check "NO". Questions 3 and 4 were not included in the 1978 survey. Two collection attempts were made in each survey. In 1991 and 1998 the answers were confirmed by personal communication of one of the investigators with all parents who had a positive response to at least one question, all parents who returned questionnaires with missing values, and with 350 randomly selected controls (negative responses to all questions). During personal communication, additional information was obtained on hospital admissions for asthma and/or wheezing from all positive responders and on the number of school days lost because of asthma and/or wheezing during the previous 2 years from current asthmatic subjects. Prevalence was calculated for current (positive answer to questions 1 and/or 2), noncurrent (positive answer to questions 3 and/or 4), and lifetime asthma (positive answer to any of the four questions). All surveys were conducted in the months of January and February for comparability.

Confidence intervals and prevalence differences were calculated and significance tests were made using the $\chi^{2}$ test for comparison of two proportions.

\section{Results}

The response rates after the second collection of questionnaires in 1991 and 1998 were $81.9 \% \quad(76.1-92.8 \%)$ and $90.5 \% \quad(78.2-$ $96.5 \%$ ) respectively. Missing values represented less than $2 \%$ of returned questionnaires. After personal communication no missing values occurred. Seventy three of 77 positive responders to question 1 in $1991(94.8 \%)$ and 126 of 131 in 1998 (96.2\%) also responded positively to question 2 . Respective values for questions 3 and 4 were 43 of $45(95.5 \%)$ and 83 of $85(97.6 \%)$.

The prevalence of current and lifetime asthma in 1978, 1991, and 1998 is shown in table 1. There were significant consecutive increases in the prevalence of asthma. Statistical significance of differences (D) and 95\% confidence intervals (95\% CI) between surveys were as follows: $\mathrm{D}_{\text {current } 1978-91}: 3.1 \%(95 \%$ CI 2.6 to 4.0$), \mathrm{p}=0.01 ; \mathrm{D}_{\text {current } 1991-98}: 1.4 \%(95 \% \mathrm{CI} 0.2$ to 2.6$), \mathrm{p}=0.02 ; \mathrm{D}_{\text {current }} 1978-98: 4.5 \%(95 \% \mathrm{CI} 3.6$ to 5.4$), \mathrm{p}=0.03 ; \mathrm{D}_{\text {non-current }} 1991-98: 0.2 \%(95 \% \mathrm{CI}$ -0.8 to 1.2$), \mathrm{p}>0.1) ; \mathrm{D}_{\text {lifetime }} 1991-98: 1.6 \%(95 \%$ CI 0.1 to 3.1$), p=0.03$.

The ratio of "current physician diagnosed asthma" over " $\geqslant 2$ episodes of current physician diagnosed wheezing not identified as asthma" was $2.2(77 / 35)$ and $2.5(131 / 53)$ in 1991 and 1998, respectively ( $p>0.1)$. Respective ratios for "non-current physician diagnosed asthma" over "non-current physician diagnosed wheezing" were $1.2(45 / 37)$ and 3.1 $(85 / 27),(p=0.04)$.

History of "ever been hospitalised" (lifetime asthma) did not change significantly between 1991 and 1998 (D: $0.6 \%$ (95\% CI -0.26 to 1.46), $\mathrm{p}>0.1)$. The mean number of school days lost because of asthma in the previous 2 years among current asthmatics and in the total sample did not change significantly between 1991 and 1998 (D: 1.05 (95\% CI -1.7 to 3.8), $\mathrm{p}>0.1$ and D: 0.03 (95\% CI -0.6 to 0.6 ), $\mathrm{p}>0.1$, respectively).

\section{Discussion}

Large sample sizes and high response rates were achieved in the three surveys. The four schools that varied between the surveys did not differ in social or environmental aspects. The age group sampled remained constant and the racial, socioeconomic, and cultural structure of the samples remained essentially unchanged.

The prevalence of current asthma or wheezing has increased in Patras approximately threefold in the 1978-91 period from $1.5 \%$ to $4.6 \%$ (mean yearly rate $0.24 \%$ ). It continued to increase until 1998 to $6.0 \%$, albeit at a slower rate $(0.20 \%$ per year).

A standard questionnaire was used in the three surveys. Written questionnaires are probably the method of choice for comparing prevalence. ${ }^{7}$ Others have shown that questions on physician diagnosed lung disease are exceptionally specific. ${ }^{8}$ The labelling of two or more episodes of wheezing as asthma will tend to overestimate asthma prevalence, but less so 
among current asthmatics. Our results may be subject to bias because of the increasing awareness of both asthma and wheezing in the community and could be influenced by parental recall or acceptance of these labels, access to health services, and physician attitudes. We expect that the last sentence of our written questionnaire and the fact that there were no questions on recurrent or persistent cough have significantly limited false positive answers. ${ }^{9}$ This is supported by the fact that the majority of physician diagnosed asthmatic subjects were also recurrent wheezers. Access to health care is unrestricted to all children and changing consultation patterns are unlikely to have influenced trends of physician diagnosed asthma since paediatricians have remained, almost exclusively, the primary and secondary care physicians of children during the last 20 years in Greece. Other studies have shown increasing prevalence of objective parameters of the disease. ${ }^{2}$ The cause for this worldwide increase is unclear $^{2-4}$ and the present study did not address this issue.

An increase in true current asthma is supported by the essentially unchanged ratio of "current physician diagnosed asthma" over "current physician diagnosed wheezing not identified as asthma" during the period 1991-8. These results counter the concern about diagnostic transfer from bronchitis to asthma. The ratio of "non-current diagnosed asthma" over "non-current wheezing not identified as asthma" significantly increased during 1991-8. This should probably be interpreted as increased labelling of wheezing of younger children (under $6-8$ years) by physicians as asthma as "total" non-current asthma (diagnosed asthma plus wheezing not identified as asthma) did not change over the same period.
The mean number of lost school days due to asthma during the previous 2 years decreased by approximately one day (15.5\%) among current asthmatics and increased by $9.7 \%$ in the general population during the period 1991-8. These differences, however, were not significant.

In conclusion, our results show a continuing increase in the prevalence of asthma over a 20 year period and support a true increase in the prevalence of current asthma. Physicians may have become more willing to diagnose wheezing as asthma in younger children during the period 1991-8. There has been no change in the burden of asthma among asthmatics and in the general population during this period in the city of Patras, although hospital admissions for asthma or wheezing have become more common in recent years.

1 Magnus P, Jaakkola JJK. Secular trend in the occurrence of asthma among children and young adults: critical appraisal
of repeated cross sectional surveys. BMF 1997;314:1795-9.

2 Burr ML, Butland BK, King S, et al. Changes in asthma Burr ML, Butland BK, King S, et al. Changes in asthma
prevalence: two surveys 15 years apart. Arch Dis Child prevalence: two sur

3 Ninan TK, Russell G. Respiratory symptoms and atopy in Aberdeen schoolchildren: evidence from two surveys 25 years apart. BMF 1992;304:873-5.

4 Omran M, Russell G. Continuing increase in respiratory symptoms and atopy in Aberdeen schoolchildren. BMf 1996;312:34.

5 Tsanakas JN, Zarkinos F, Papastavrou T, et al. Prevalence of asthma among Greek schoolchildren. Eur Respir 7 1991; 4(Suppl):524s.

6 Papalambrou DG. Prevalence of childhood asthma (in Greek). Doctoral Thesis, Patras, 1984

7 Pekkanen J, Pearce N. Defining asthma in epidemiological studies. Eur Respir f 1999;14:951-7.

8 Burney P, Laitinen L, Perdrizet S, et al. Validity and repeatability of the IUATLD (1984) bronchial symptoms questionnaire: an international comparison. Eur Respir $\mathcal{F}$ 1989;2:940-5.

9 Comino E, Mitchell CA, Bauman A, et al. Asthma management in eastern Australia, 1990 and 1993. Med f Aust 1996;164:403-6. 